\title{
Foreign Entry and Multi-Period Bank Competition Based on Collateral View
}

\author{
Xudong Chen ${ }^{*}$, Yong Zeng \\ School of Management and Economics, University of Electronic Science and Technology of China, \\ Chengdu, China \\ Email: "chenxudong198401@163.com
}

Received January $16^{\text {th }}, 2013$; revised February $15^{\text {th }}, 2013$; accepted February $22^{\text {nd }}, 2013$

\begin{abstract}
This paper constructs the multi-period model of spatial bank competition between the local bank and the foreign bank with financing cost (efficiency) advantage, the results show that: 1) when the amount of the high risk borrowers in the marker reaches a threshold, both banks will use collateral as screening device to distinguish different risk borrowers, only low risk borrowers will borrow money from the bank; 2) the space distance (production differentiation) can help local bank confront the foreign bank's cost (efficiency) advantage. Further comparative static analysis shows: the bank's profit decreases with its financing cost, and the bank will require higher loan rate and less collateral with its financing cost increasing; Decreasing transaction cost and better legal environment will facilitate the bank to require more collateral and lower loan rate.
\end{abstract}

Keywords: Multi-Period Bank Competition; Collateral; Screening

\section{Introduction}

In the last few decades, the active liberalization of global banking markets has led to a sharp increase in the foreign banks' entry into many countries. Claessense et al. (2008) indicates that from 1995 to 2006, the number of foreign banks and their market shares of Latin America, Eastern Europe and some regions in low and middle-income countries of central Asia increase rapidly. Moreover, the foreign banks' market share in some countries of Eastern Europe accounts for more than $80 \%$. In China, banking system has been reformed fast and deeply recently, the introduction of foreign strategic investors is central to Chinese bank reform (Zhu et al., 2008). In 2001 China joined the WTO, we promised to open our financial market completely to the foreign investor in five years later. In 2006, all the non-prudential restrictions on foreign banks' entry into China were cancelled, consequently foreign banks are developing quickly in China. By the end of 2011, 37 banks from 14 countries and regions have established locally incorporated foreign banks, the gross assets of foreign banks in China increased by $23.6 \%$ year-on-year. It is worthy to analyze how the foreign banks' entry impact domestic banks.

Lending is core business of commercial bank, the traditional financial intermediation theory shows that information asymmetry is key point in bank lending. On the one hand, bank and borrower have asymmetric information about the ability of borrower to repay loans, on the other hand, different banks have asymmetric information about the ability of borrower to repay loans because of their different lending relationship. Dell Ariccia (2001) constructs the framework of multi-period model of spatial bank competition, which shows that the information asymmetries are important determinates of the bank competetion. Li (2010) considers multi-period credit competition and steady state between the local bank with information advan-

${ }^{*}$ Corresponding author. tages and the foreign bank with the financing cost advantage, and the conclusion shows that the local bank's information advantage can not hinder the foreign bank' entry. Deng (2010) studies the strategic cooperation decision of the foreign bank and domestic bank through real option method, results show that besides the high growth and scale of the local credit markets, the chance of foreign bank acquiring local bank in the future will be a significant reason for foreign bank's entry into China. Hauswald \& Marquez $(2003,2006)$ analyzes how information asymmetry affects the structure of the bank competition and the interest rate, through different screening ability reflecting information asymmetry between both banks. Further more, Lehner $(2008,2009)$ analyzes how the size of market and screening ability affect entry mode choice. Gormley (2007) considering the favorable and adverse impact exerted by foreign bank's entry on local market in pure strategy framework.

Another researches analyzing information asymmetry in bank competition find that collateral can be used as a screening device to deal with information asymmetry, famous for such works as Bester (1985), Bensanko \& Thakor (1987a, 1987b), which show that: low risk borrowers are more willing to provide collateral to the bank than high risk borrowers so as to show that themselves are low risk. The reason is that the higher failure probability of high risk borrowers' investment leads high risk borrowers more reluctant to provide collateral to the bank. Based on the above conclusion it shows that collateral can help bank exactly distinguish different risk borrowers so as to reduce the bank to suffer from the loss caused by the adverse selection. However, Barro (1976) also shows that collateral is costly to be used as screening device in distinguishing different risk borrowers, because when the borrowers investment fails and borrowers are not able to repay the loans, the bank will take possession of and liquidating the collateral, which incurs a loss between the bank and the borrowers. Consequently, the collateral value for the bank is lower than that for the borrowers. 
Hainz (2008) analyzing the loans of 70 countries shows that: when the bank competition is weak, the bank may require the borrowers to provide collateral. Further researches as Sengupta (2007, 2009) study bank competition between informed incumbent bank and uninformed foreign bank, which indicates that: both ex ante better information and ex-post stronger legal protection facilitate foreign bank's entry.

However previous research about collateral research are constructed as single period, while the bank competition between local bank and foreign bank is dynamic, the bank will make optimal decisions based on its future expected return. In this sense only can multi-period and dynamic bank competition describe real competition between the two banks. Besides, to the best of my knowledge, there are few papers that consider bank competition where interest rate and collateral are the strategic variables of competition.

In this paper bank competition is constructed as interaction between asymmetrically informed banks: local bank is more familiar with the local credit market, while foreign has financeing cost (efficiency) advantage, and both banks use collateral as a screening device to distinguish different risk borrowers. At the base of Dell Ariccia (2001) and Sengupta (2007), we extend to discuss each bank's optimal credit strategy in the multi-period and dynamic bank competition, the study shows that: when the ratio of high risk borrowers in the markets exceed a certain critical value, both banks require borrowers to provide collateral and pay loan rate, so only low risk borrowers would like to borrow money from bank, high-risk borrowers give up borrowing money from any bank; multi-period and dynamic bank competition will eventually achieve steady state, in the steady state the situation in every period is the same, the space distance (production differentiation) can help local bank confront foreign bank's cost advantage. Further comparative static analysis shows: the local bank's profit becomes smaller with bigger financing cost, and bank will require higher rate and less collateral with its financing costs increasing, increasing transaction cost will facilitate the bank to require higher interest rate and lower collateral. Better legal environment facilitates the bank to require more collateral and lower interest rate.

The rest of is arranged as following: Section 2 lays out the basic hypothesis of bank credit competition; Section 3 establishes the bank competition, Section 4 is the comparative static analysis. Section 5 provides the results. All proofs are listed in the Appendix.

\section{Basic Assumption}

Similarly as Sengupta (2007), there are two banks in the credit market: bank $I$, the local bank which exists a long time in the market; bank $E$, the foreign bank who entered the market right now, two banks locates two endpoints of a line of measure 1 , all borrowers uniformly distribute along the line.

Local bank and foreign bank's financing costs are respectively $\rho^{I}$ and $\rho^{E}$. Foreign bank has financing cost (efficiency) advantage, namely $\rho^{E}<\rho^{I}$. Borrowers will borrow 1 from the bank and invest a project which generates gains $X$ with probability $1-\theta$ and 0 with probability $\theta$. Banks face two kinds of different risk borrowers: fraction $v$ of high risk borrowers whose probability of successful project is $1-\theta_{H}$ and fraction $1-v$ of low risk borrowers whose probability of successful project is $1-\theta_{L}$, where $0<\theta_{L}<\theta_{H}<1$. We assume that the low risk borrowers (good borrowers) are worthy to lending (i.e., $\left.\left(1-\theta_{L}\right) X-\rho^{j}>0, j=I, E\right)$ and the high risk borrowers (bad borrowers) are unworthy to lending (i.e., $\left.\left(1-\theta_{H}\right) X-\rho^{j}<0, j=I, E\right)$, bank and borrower have asymmetric information about the risk type of borrowers, namely before the bank loans to the borrowers, all borrowers know their risk types, while the bank does not know their risk types.

Following Sengupta (2007), bank provides a loan contract $(R, C)$ to the borrower, which specifies that borrower need provide an amount of collateral $C$ to the bank and pay interest rate $R$. In detail, if the project successes, borrower pays interest rate $R$ to the bank and collateral $C$ will be paid to the bank if the project fails. According to the Barro (1976), the disparity in collateral valuation between the borrower and the bank by noting as $\beta$, namely the value of the collateral $C$ which the borrower provides becomes $\beta C$ for the bank, Where $0 \leq \beta<1$. The size of the discount rate $\beta$ reflects the legal environment of the host country. Poor legal environment means smaller discount rate. When the bank provide the loan contract $(R, C)$ to borrowers, the bank's expected profit function is given by $\pi(R, C)=(1-\theta) R+\beta \theta C-\rho$, the expected revenue of borrowers is given by

$u(R, C)=(1-\theta)(X-R)-\theta C$, so the above loan contract

$(R, C)$ will yield a surplus $(1-\theta) X-\rho-(1-\beta) \theta C$. The surplus is the total profit of the investment, part of which will be assigned to the bank and the other part will be assigned to the borrower. Meanwhile, we find that the use of the collateral will lead a loss of society surplus $(1-\beta) \theta C$, which is just the price of the use of collateral. As Sengupta (2007) shows, collateral can be used as a perfect screening device to help bank exactly distinguish the borrowers' risk type, namely low risk borrower would like to provide more collateral and pay lower rate $R$, while high risk borrower would like to pay higher rate $R$ and provide less collateral, the loss of society surplus $(1-\beta) \theta C$ can be thought as the cost of screening. Bank $j$ provides the loan contract $\left(R_{k}^{j}, C_{k}^{j}\right)$ to the borrower $k$. For simplicity, borrowers are assumed to have unconstrained access to collateral. The borrowers' reservation utility is 0 , all borrowers are live for two periods, both banks face only new borrowers in the first period. In each period later, there are new and old borrowers in the market for both banks, the new borrowers derive from the credit market growth (or recession), and the old borrowers come from the new borrowers in the previous period, and the old borrowers disappear in the end of this period; obviously, all the new borrowers will disappear in the two period later. Among the new borrowers the ratio of high risk and low risk is $v:(1-v)$. In each period the amount of new borrowers is $\lambda$ times that of old borrowers, namely the ratio of new borrowers to old borrowers in each period is $\lambda: 1$.

Borrowers still need to pay transaction cost $w_{I} X$ besides interest rate and collateral, $x$ is the distance between borrower and bank $I, w_{I}$ is the unit transaction cost for borrower lending form bank $I$. According to Dell Ariccia (2001), transaction costs can be viewed as a measure of degree of product differentiation. For example the distances between the borrower and bank $I$, bank $E$ are respectively $x$ and $1-x$, the transaction costs of the borrower lending from bank $I$ and bank $E$ are respectively $w_{I} x, w_{E}(1-x)$. Because local bank $I$ has enough understanding about the local economic and cultural environment, together with wide local customer resources, and mostly set up a relatively stable lending relationship. So local bank is more familiar to borrowers, while foreign bank is not familiar with borrowers for its new entry. In other 
words compared with foreign bank, the local bank has the information advantage. The transaction costs of two banks reflect the information asymmetry between two banks, local bank is more familiar to the market so its transaction cost is smaller than that of foreign bank. When bank $I$ provides loan contract $\left(R_{k}^{I}, C_{k}^{I}\right)$ to the borrower whose risk type is $k$, the expected profit of borrower is $u_{k}\left(R_{k}^{I}, C_{k}^{I}\right)-w_{I} X$. Similarly when bank $E$ provide loan contract $\left(R_{k}^{E}, C_{k}^{E}\right)$ to the borrower, the expected profit of borrower is $u_{k}\left(R_{k}^{E}, C_{k}^{E}\right)-w_{E}(1-x)$. A borrower located at a distance $x$ from bank $I$ is indifferent between lending from bank $I$ and lending from bank $E$ if

$$
u_{k}\left(R_{k}^{I}, C_{k}^{I}\right)-w_{I} x=u_{k}\left(R_{k}^{E}, C_{k}^{E}\right)-w_{E}(1-x)
$$

\section{Bank Competition of the Basic Model}

\section{Single Period Competition}

In a single period bank competition, both banks face only new borrowers, borrowers know their risk type, but both banks cannot distinguish different risk borrowers. Neither bank has old borrowers (old borrowers are those borrowers who have lending relationship with the bank), bank need seek optimal strategies to maximize their expected profits according to the current situation. The competition process is as follows: first each bank decides its loan rate $R$ and requires borrowers to provide collateral $C$, then each borrower maximizes its expected profit by choosing which bank to borrow money from. Higher rate $R$ and more collateral $C$ can increase the expected profit from per borrower, but more borrowers will apply loan to its rival bank, so both bank will make an appropriate loan rate $R$ and collateral $C$ to maximize the bank's expected profit.

Similarly as Sengupta (2007), we analyze the condition that both banks will use collateral as screening device. We can get the Proposition 1 whose proof can be seen in the Appendix A.

Proposition 1: if $\frac{u_{H}^{j}}{1-\theta_{H}} \leq \frac{u_{L}^{j}}{1-\theta_{L}}$, when ratio of the high risk borrowers in the new borrowers satisfies $v \geq v_{1}$,

where $v_{1}=\frac{(1-\beta) \theta_{L}\left(1-\theta_{L}\right)}{\theta_{H}-\beta \theta_{L}-(1-\beta) \theta_{L}^{2}}$, both banks will use collateral as screening device, bank $j$ will provide two loan contracts

$$
\begin{aligned}
& \left\{\left(R_{H}^{j}, C_{H}^{j}\right),\left(R_{L}^{j}, C_{L}^{j}\right)\right\} \text { to the borrowers, where } \\
& R_{L}^{j}=X-\frac{\theta_{H} u_{L}^{j}}{\theta_{H}-\theta_{L}}+\frac{\theta_{L} u_{H}^{j}}{\theta_{H}-\theta_{L}}, C_{L}^{j}=\frac{\left(1-\theta_{H}\right) u_{L}^{j}-\left(1-\theta_{L}\right) u_{H}^{j}}{\theta_{H}-\theta_{L}}, \\
& R_{H}^{j}=X-\frac{u_{H}^{j}}{1-\theta_{H}}, C_{H}^{j}=0
\end{aligned}
$$

As banks and borrowers have ex ante information asymmetry, namely bank cannot distinguish the risk type of the borrowers, if bank do not use collateral as a screening device, bank has to require all borrowers the same interest rate $R$, and the bank will suffer from the loss caused by adverse selection. If bank use collateral as a screening device, the screening cost is $(1-\beta) \theta C$. so each bank faces a trade-off between loss caused by adverse selection and the screening cost, if the amount of high risk borrowers is bigger, namely there are much more bad borrowers in the market, the loss caused by adverse selection will the be more than the screening cost caused by using collateral, then the bank prefers to use collateral as a screening device. If the amount of high risk borrowers is smaller, bank prefers the same interest rate for all borrowers, in this case there are enough good borrowers, bank would not like to require borrowers to provide collateral.

As contract theory shows that: "to any Bayesian Nash equilibrium of a game of incomplete information, there exists a payoff-equivalent revelation mechanism that has an equilibrium where the players truthfully report their types" (revelation principle). Bank can provide two loan contracts, one contract is higher loan rate and lower collateral and another contract is higher collateral and lower loan rate. The high risk borrowers are willing to choose the first contract and the low risk borrowers are willing to choose the second contract. By the mechanism offered by the bank, borrowers will not hide their risk type.

For simplicity, in the subsequent study we assume $v \geq v_{1}$, namely the amount of the high risk borrowers in the market is large, both banks are willing to use collateral as a screening device. So banks can accurately distinguish the different risk of two kinds of borrowers. Because high risk borrowers are unworthy to lend, the bank only lend money to low risk borrowers. We can get the Proposition 2 whose proofs can be seen in the Appendix B.

Proposition 2: when the bank $j$ provides loan contract $\left(R_{L}^{j}, C_{L}^{j}\right)$ to all the borrowers so that the low risk expected revenue is no less than $u_{L}^{j}$, only low risk borrowers lend from bank $j$, high-risk borrowers will not lend from any bank. The expected profits of bank $j$ is give

by $\pi_{L}^{j}=(1-v)\left[\left(1-\theta_{L}\right) X-(1+M) u_{L}^{j}-\rho^{j}\right]$,

where $M=\frac{(1-\beta) \theta_{L}\left(1-\theta_{H}\right)}{\theta_{H}-\theta_{L}}$. The interest rate and collateral are respectively:

$$
R_{L}^{j}=X-\frac{\theta_{H} u_{L}^{j}}{\theta_{H}-\theta_{L}}, C_{L}^{j}=\frac{\left(1-\theta_{H}\right) u_{L}^{j}}{\theta_{H}-\theta_{L}}
$$

From (3) we can get the relationship between the loan rate and collateral

$$
R_{L}^{j}+\frac{\theta_{H}}{1-\theta_{H}} C_{L}^{j}=X
$$

The screening cost can be shown as follows

$$
M u_{L}^{j}=\frac{(1-\beta) \theta_{L}\left(1-\theta_{H}\right)}{\theta_{H}-\theta_{L}} u_{L}^{j}=(1-\beta) \theta_{L} C_{L}^{j}
$$

According to Proposition 2, both banks offer only one contract $\left(R_{L}^{j}, C_{L}^{j}\right)$, only low risk borrowers will borrow from the bank. No matter high risk borrowers lend or do not lend, their expected profits are 0 . So high risk borrowers do not lend from any bank, this is the revelation principle. Meanwhile we can find the screening cost is $M u_{L}^{j}$, bigger $u_{L}^{j}$ means bigger screening cost, then the expected profit of the bank become less. By (4) we know bank will decrease interest rate together with more collateral. By (5) we find that more collateral required by the bank, the expected profit for the borrowers is more, but the screening cost is big, the bank's profit is less. So bank will 
choose the least collateral so long as high risk borrowers are not willing to apply loan to the bank. In addition through the Proposition 2 we can know that the optimal loan contract $(R, C)$ provided by the banks is one-to-one correspondence with the expected revenue of the borrowers $u_{L}^{j}$, that is to say, every loan contract $(R, C)$ offered by the bank can lead one and only one $u_{L}^{j}$. In the other hand, for each $u_{L}^{j}$ there exists unique optimal loan contract $(R, C)$. The bank selects $R, C$ as its decision variables in the previous researches, based on the Proposition 2, bank can choose $u_{L}^{j}$ rather than its decision variable $R, C$, which can simplify our analysis.

Consequently, we obtain the equilibrium of the single period bank competition as Proposition 3, proofs can be seen in the Appendix C.

Proposition 3: If

$-(1+M)\left(2 w_{E}+w_{I}\right)<\rho^{E}-\rho^{I}<(1+M)\left(2 w_{I}+w_{E}\right)$, in the single bank competition, there is a point $x_{L}^{s}$, the lower risk borrowers located in the $x_{L}^{s}$ left lend from bank I, lower risk borrowers located in the $x_{L}^{s}$ right lend from bank $E$, the expected profits of two banks are:

$$
\begin{aligned}
& \Pi_{\mathrm{new}}^{s I}=\frac{\lambda(1-v)}{9(1+M)\left(w_{I}+w_{E}\right)}\left[\rho^{E}-\rho^{I}+(1+M)\left(w_{I}+2 w_{E}\right)\right]^{2}(6) \\
& \Pi_{\mathrm{new}}^{s E}=\frac{\lambda(1-v)}{9(1+M)\left(w_{I}+w_{E}\right)}\left[\rho^{I}-\rho^{E}+(1+M)\left(w_{E}+2 w_{I}\right)\right]^{2}(7)
\end{aligned}
$$

where

$$
x_{L}^{s}=\frac{1}{3\left(w_{I}+w_{E}\right)(1+M)}\left[\rho^{E}-\rho^{I}+\left(w_{I}+2 w_{E}\right)(1+M)\right]
$$

The conclusion shows that space distance (or production differentiation) can confront against foreign bank's cost (efficiency) advantage.

\section{Multi-Period and Dynamic Competition}

In brief, the main difference between multi-period and dynamic competition and single period bank competition is that bank will determine the optimal decision according to their future expected profit. The competition process is indicated as follows: first, both banks decide interest rate $R$ and collateral $C$, and the new low risk borrowers decide which bank to borrow money to maximize the expected profit. For the old borrowers of each bank itself, the bank must offer at least the profit that its rival bank can offer in order to avoid their old borrowers to borrow money from its rival bank as a new borrower. So for its old borrowers, each bank will make different decision from new borrowers. For the old borrowers, since lending relationship has been set up with the original bank and the profit given by the original bank is the same as the profit given by the rival bank, the old borrowers will choose to loan from the original bank. Therefore, for each bank, their old borrowers' interest rate and collateral is no longer bank's decision variable, the competition between two banks is only embodied in the new borrowers' competition.

Due to $v \geq v_{1}$, banks face new borrowers market and old customers who are identified as high risk borrowers by the competitors, intuitively there are too many bad new borrowers in the market. So both banks require all borrowers to provide collateral to distinguish two kinds of customers.

In the process of competition period, we construct dynamic competitive framework of bank competition where borrowers are alive for two periods, the total profit of the bank derives from the following four categories borrowers:

a) The initial old borrowers (no old borrowers in the first period, there are old borrowers in the every period later);

b) The new borrowers of the first period (including the new borrowers of the market and the initial high risk old borrowers who are screened as high risk borrowers by the rival bank in the earlier period);

c) The old borrowers of the second period (initial old borrowers in the first period disappear in the second period, the old borrowers derive from the new borrowers of the first period);

d) The new borrowers of the second period (including new borrowers in the market and the old borrowers derive from the new borrowers of the second period).

Because both banks require borrowers to provide collateral and pay interest rate, only low risk borrowers will borrow money, so no matter local bank or foreign bank, their profits are from low risk borrowers. We note the discount rate as $\delta$, and $0<\delta<1$, we can get the Proposition 4 that is proved in the Appendix D.

\section{Proposition 4: If}

$$
\begin{aligned}
-\left[(1-\delta) w_{I}+2 w_{E}\right](1+M) & <(1+\delta)\left(\rho^{E}-\rho^{I}\right) \\
& <\left[(1-\delta) w_{E}+2 w_{I}\right](1+M)
\end{aligned}
$$

in multi-period and dynamic bank competition, there is a point $x_{L}^{m}$, low risk of borrowers located in the $x_{L}^{m}$ left loan from bank $I$, low risk of borrowers located in the $x_{L}^{m}$ right loan from bank $E$, and both banks only provide only a contract, only low risk borrowers are willing to borrow money, the expected profits of the two bank are respectively

$$
\begin{aligned}
& \Pi_{\text {new }}^{m I}= \frac{\left[(1-\delta)(1+\delta \lambda)+2 \delta-\frac{\delta}{2}(1+\delta)\right] \lambda(1-v)}{(3-\delta)^{2}(1+\delta)\left(w_{I}+w_{E}\right)(1+M)} \\
& \cdot\left\{(1+\delta)\left(\rho^{E}-\rho^{I}\right)+(1+M)\left[(1-\delta) w_{I}+2 w_{E}\right]\right\}^{2} \\
& \Pi_{\text {new }}^{m E}=\frac{\left[(1-\delta)(1+\delta \lambda)+2 \delta-\frac{\delta}{2}(1+\delta)\right] \lambda(1-v)}{(3-\delta)^{2}(1+\delta)\left(w_{I}+w_{E}\right)(1+M)} \\
& \cdot\left\{(1+\delta)\left(\rho^{I}-\rho^{E}\right)+(1+M)\left[(1-\delta) w_{E}+2 w_{I}\right]\right\}^{2}
\end{aligned}
$$

where

$$
\begin{aligned}
x_{L}^{m}= & \frac{1}{(3-\delta)(1+M)\left(w_{I}+w_{E}\right)} \\
& \cdot\left\{(1+\delta)\left(\rho^{E}-\rho^{I}\right)+\left[(1-\delta) w_{I}+2 w_{E}\right](1+M)\right\}
\end{aligned}
$$

The above propositions tell us that both banks use collateral as screening device. Further more, the interest rate and the collateral are different for two banks. As collateral required by the bank, the high risk borrowers will not apply loan from any bank, only low risk borrowers will loan from the bank, so collateral is an accurate screening device, this is the revelation principle.

\section{Comparative Static Analysis}

This section are comparative static analysis, analyzing how the financing cost, the transaction cost and legal environment 
influence the profit, interest rate and collateral.

\section{Financing Cost}

Through the Proposition 4 we can get the financing cost's effect on the banks' profit, interest rate and collateral. Proof can be seen in the Appendix D.

\section{Corollary 1:}

$$
\frac{\partial \Pi_{\text {new }}^{m j}}{\partial \rho^{j}}<0, \frac{\partial R^{j}}{\partial \rho^{j}}=\frac{\partial R^{j}}{\partial u^{j}} \frac{\partial u^{j}}{\partial \rho^{j}}>0, \frac{\partial C^{j}}{\partial \rho^{j}}=\frac{\partial C^{j}}{\partial u^{j}} \frac{\partial u^{j}}{\partial \rho^{j}}<0
$$

The above conclusions show that, the local banks' profit decreases with its financing costs increasing, however, while foreign bank's profits and market share increase. In fact, the local bank financing cost increases, its efficiency become bad and its competitiveness become weak, which leads smaller market share and less profit. Meanwhile, bank will require higher rate and less collateral with its financing costs increasing. In the other words, the decreasing efficiency of the bank reduces its desire to use collateral, consequently reduces the profit of the borrowers.

\section{Transaction Cost}

Through the Proposition 4 we can get transaction cost's effect on the banks' profit, interest rate and collateral. Proof can be seen in the Appendix D.

\section{Corollary 2:}

if $(1+\delta)\left(\rho^{E}-\rho^{I}\right)+(1+M)\left[2 \delta w_{E}-(1-\delta) 2 w_{I}\right]>0$, $\frac{\partial \Pi_{\text {new }}^{m I}}{\partial w_{I}}<0$;

if $(1+\delta)\left(\rho^{E}-\rho^{I}\right)+(1+M)\left[2 \delta w_{E}-(1-\delta) 2 w_{I}\right] \leq 0$, $\frac{\partial \Pi_{\text {new }}^{m I}}{\partial w_{I}} \geq 0$

Corollary 3:

$$
\frac{\partial R^{j}}{\partial w_{j}}=\frac{\partial R^{j}}{\partial u^{j}} \frac{\partial u^{j}}{\partial w_{j}}>0, \frac{\partial C^{j}}{\partial w_{j}}=\frac{\partial C^{j}}{\partial u^{j}} \frac{\partial u^{j}}{\partial w_{j}}<0
$$

Corollary 2 shows that when the transaction cost is small, both banks compete intensely for borrowers, increasing transaction cost means the weak competitiveness of the bank, so the profit of the bank is less. When the transaction cost is big, the bank competition becomes weak, both banks prefer monopolizing their borrowers rather than competing with its rival. Intuitively speaking, the increasing transaction cost means that the borrowers have to spend more to borrow money from any bank. That is to say, the borrowers who are captured by the local bank are more reluctant to borrow from foreign bank. In other words, the borrowers are more captive by the local bank. then both banks begins to exploit its borrowers just as parts of markets are monopolized by the local bank and parts of market are monopolized by the foreign bank, so the profit bank of both banks increase. Consequently, the profit of the borrowers should be less.

Corollary 3 shows that increasing transaction cost will facilitate the bank to require higher interest rate and lower collateral. Increasing transaction cost implies that the bank competition is less intense, as described before, the screening cost by using collateral as a screening device is $(1-\beta) \theta C$, so the bank prefers as few collateral as possible so long as high risk borrowers are not willing to loan from the bank, then the bank will ask borrowers provide less collateral and higher rate. Under the circumstances, bank will obtain more profit but profits of borrowers are less.

\section{Legal Environment}

Through the Proposition 4 we can get legal environment's effect on the interest rate and collateral. Proof can be seen in the Appendix D.

Corollary 4:

$$
\frac{\partial R^{j}}{\partial \beta}=\frac{\partial R^{j}}{\partial u^{j}} \frac{\partial u^{j}}{\partial \beta}<0, \frac{\partial C^{j}}{\partial \beta}=\frac{\partial C^{j}}{\partial u^{j}} \frac{\partial u^{j}}{\partial \beta}>0
$$

Better legal environment means bank use collateral as the screening device less costly, namely the screening is more efficient, which makes the bank be willing to require more collateral and lower interest rate.

\section{Conclusion}

This paper considers the multi-period model of spatial bank competition between the local bank and the foreign bank with cost (efficiency) advantage and explores the effect of foreign entry and bank competition on firms' access to credit, the results show that: when the amount of the high risk borrowers in the marker is more enough, both banks prefer to use collateral as screening device to distinguish different risk borrowers rather than suffering the loss caused by adverse selection, only the low risk borrowers will apply loan from the bank; the space distance (production differentiation) can help local bank confront against foreign bank's cost advantage.

Further comparative static analysis shows: the local bank's profit decreases with its financing cost, and the bank will require higher rate and less collateral with its financing costs increasing. Increasing transaction cost will facilitate the bank to require higher interest rate and lower collateral. Better legal environment facilitates the bank to require more collateral and lower interest rate.

Combined with the reality situation in China, the non-prudential foreign banks' entry restrictions are removed in 2006, foreign banks can establish locally-incorporated foreign bank in China. Compared with domestic banks, foreign banks enjoy super national treatment on the tax. Moreover, foreign banks have much better ability of converting deposits to loans. So compared with domestic banks, foreign banks have cost (efficiency) advantage. However domestic banks also have their competitive advantage: domestic banks are more familiar with local national circumstances and have wide borrowers resources. Further more domestic banks have established a relatively stable and long-term lending relationship with many local firms. Under the same conditions firms are apt to borrow money from domestic banks. In short, domestic banks are more familiar with the local market, the domestic banks' transaction cost is less than foreign banks' transaction cost, and foreign banks have cost (efficiency) advantage, according to the Proposition 4 shows that some of good borrowers (low risk borrowers) accept loan from domestic bank, other good borrowers accept loan from foreign bank, all bad borrowers (high risk borrowers) can not accept any loan from either bank. For borrowers, better 
legal environment and higher efficiency of the bank will require borrowers to pay lower loan rate and provide more collateral so that the borrowers' circumstances are improved.

\section{REFERENCES}

Barro, R. (1976). The loan market, collateral and rates of interest. Journal of Money, Credit, and Banking, 8, 439-456. doi:10.2307/1991690

Besanko, D., \& Thakor, A. (1987a). Collateral and rationing: Sorting equilibria in monopolistic and competitive credit market. International Economic Review, 28, 671-689. doi:10.2307/2526573

Besanko, D., \& Thakor, A. (1987b). Competitive equilibrium in the credit market under asymmetric information. Journal of Economic Theory, 42, 167-182. doi:10.1016/0022-0531(87)90108-6

Bester, H. (1985). Screening vs. rationing in credit markets with imperfect information. American Economic Review, 75, 850-855.

Claessens, S., Van Horen, N., Gurcanlar, T., \& Mercado, J. (2008). Foreign bank presence in developing countries 1995-2006: Data and trends. Working Paper.

http://papers.ssrn.com/sol3/papers.cfm?abstract_id=1107295

Dell Ariccia, G. (2001). Asymmetric information and the structure of the banking industry. European Economic Review, 45, 1957-1980. doi:10.1016/S0014-2921(00)00085-4

Deng, G.-J., Zeng, Y., Li, Q., \& He, J. (2012). Strategic cooperation decision of the foreign bank and China's bank. Journal of Management Sciences in China, 15, 71-85.

Gormley, T. (2007). Cost information, foreign entry and credit access.
Working Paper, St. Louis: Washington University.

Hainz, C., Weill, L., \& Godlewski, J. (2008). Bank competition and collateral: Theory and evidence. Bank of Finland Research Discussion Papers.

Hauswald, R., \& Marquez, R. (2003). Information technology and financial services competition. The Review of Financial Studies, 16, 921-948. doi:10.1093/rfs/hhg017

Hauswald, R., \& Marquez, R. (2006). Competition and strategic information acquisition in credit markets. The Review of Financial Studies, 19, 967-1000. doi:10.1093/rfs/hhj021

Lehner, M. (2008). Entry of foreign banks and their impact on the host countries. Journal of Comparative Economics, 36, 430-452. doi:10.1016/j.jce.2008.02.002

Lehner, M. (2009). Entry mode choice of multinational banks. Journal of Banking \& Finance, 33, 1781-1792. doi:10.1016/j.jbankfin.2009.03.009

Li, Q., Zeng, Y., \& Liu, B. (2010). Foreign entry and multiple-stage credit competition in bank industry: A steady-state model. China Economic Review, Forthcoming.

Sengupta, R. (2007). Foreign entry and bank competition. Journal of Financial Economics, 84, 502-528. doi:10.1016/j.jfineco.2006.04.002

Sengupta, R. (2009). Lending to uncreditworthy borrowers. Working Paper, Federal Reserve Bank of St. Louis.

Zhu, Y.-Y., Zeng, Y., Li, P., \& He, J. (2008). Introducing foreign strategic investor into Chinese banks: Background, debate and review. Management World, 1, 22-37. 


\section{Appendix A: The Proof of Proposition 1}

We consider the following two loan contracts $\left\{\left(R_{H}^{j}, C_{H}^{j}\right),\left(R_{L}^{j}, C_{L}^{j}\right)\right\}$ offered by the bank, so that the revenues of low risk and high risk borrowers are respectively are no less than $u_{L}^{j}, u_{H}^{j}$.

Then we maximize the bank's profit by choosing appropriate loan rate and collateral:

$$
\begin{aligned}
& \pi^{j}=\max \{ v\left[\left(1-\theta_{H}\right) R_{H}^{j}+\beta \theta_{H} C_{H}^{j}-\rho^{j}\right] \\
&\left.+(1-v)\left[\left(1-\theta_{L}\right) R_{L}^{j}+\beta \theta_{L} C_{L}^{j}-\rho^{j}\right]\right\}
\end{aligned}
$$

s.t

$$
\begin{aligned}
& u_{H}^{j}\left(R_{H}^{j}, C_{H}^{j}\right) \geq u_{H}^{j}\left(R_{L}^{j}, C_{L}^{j}\right) \\
& u_{L}^{j}\left(R_{L}^{j}, C_{L}^{j}\right) \geq u_{L}^{j}\left(R_{H}^{j}, C_{H}^{j}\right) \\
& u_{H}^{j}\left(R_{H}^{j}, C_{H}^{j}\right) \geq u_{H}^{j} \\
& u_{L}^{j}\left(R_{L}^{j}, C_{L}^{j}\right) \geq u_{L}^{j}
\end{aligned}
$$

Similar as Sengupta (2007), we solve the above maximization step by step.

First $C_{H}^{j}=0$, intuitively high-risk borrowers hope to pay higher interest rate and provide less collateral. Second, (A2) is tight. Third, (A5) is tight, namely $u_{L}^{j}\left(R_{L}^{j}, C_{L}^{j}\right)=u_{L}^{j}$.

So the above optimization problem can be expressed as:

$$
\begin{aligned}
\pi^{j}=\max \{ & v\left[\left(1-\theta_{H}\right) R_{H}^{j}-\rho^{j}\right] \\
+ & \left.(1-v)\left[\left(1-\theta_{L}\right) R_{L}^{j}+\beta \theta_{L} C_{L}^{j}-\rho^{j}\right]\right\}
\end{aligned}
$$

s.t

$$
\begin{aligned}
& R_{H}^{j}-R_{L}^{j}=\frac{\theta_{H}}{1-\theta_{H}} C_{L}^{j} \\
& R_{H}^{j}-R_{L}^{j} \geq \frac{\theta_{L}}{1-\theta_{L}} C_{L}^{j} \\
& R_{H}^{j} \leq X-\frac{u_{H}^{j}}{1-\theta_{H}} \\
& R_{L}^{j}+\frac{\theta_{L}}{1-\theta_{L}} C_{L}^{j}=X-\frac{u_{L}^{j}}{1-\theta_{L}}
\end{aligned}
$$

The above problem is a linear programming problem with three variables, as $\frac{u_{H}^{j}}{1-\theta_{H}}<\frac{u_{L}^{j}}{1-\theta_{L}}$, we get, if $v \geq v_{1}$, the bank will use collateral to distinguish two different types of borrowers, and the rate and collateral are respectively

$$
\begin{aligned}
& R_{H}^{j}=X-\frac{u_{H}^{j}}{1-\theta_{H}}, C_{H}^{j}=0, R_{L}^{j}=X-\frac{\theta_{H} u_{L}^{j}}{\theta_{H}-\theta_{L}}+\frac{\theta_{L} u_{H}^{j}}{\theta_{H}-\theta_{L}}, \\
& C_{L}^{j}=\frac{\left(1-\theta_{H}\right) u_{L}^{j}-\left(1-\theta_{L}\right) u_{H}^{j}}{\theta_{H}-\theta_{L}}
\end{aligned}
$$

\section{Appendix B: Proposition 2's Proof}

If $v \geq v_{1}$, both banks choose to use collateral to distinguish different risk borrowers, as high risk borrowers are unworthy to lend, obviously the bank is not willing to loan to high-risk borrowers, thus high risk borrower's revenue is 0 , assuming that the revenue of low risk borrowers loaning to bank $j$ is $u_{L}^{j}$, we calculate the bank's profits:

$$
\left.\pi_{L}^{j}=\max (1-v)\left[\left(1-\theta_{L}\right)\right) R_{L}^{j}+\beta \theta_{L} C_{L}^{j}-\rho^{j}\right]
$$

s.t

$$
\begin{array}{r}
u_{H}^{j}\left(R_{L}^{j}, C_{L}^{j}\right)=0 \\
u_{L}^{j}\left(R_{L}^{j}, C_{L}^{j}\right)=u_{L}^{j}
\end{array}
$$

Similar as Proposition 1, we can get

$$
\pi_{L}^{j}=(1-v)\left[\left(1-\theta_{L}\right) X-(1+M) u_{L}^{j}-\rho^{j}\right]
$$

where

$$
M=\frac{(1-\beta) \theta_{L}\left(1-\theta_{H}\right)}{\theta_{H}-\theta_{L}}, R_{L}^{j}=X-\frac{\theta_{H}}{\theta_{H}-\theta_{L}} u_{L}^{j}, C_{L}^{j}=\frac{1-\theta_{H}}{\theta_{H}-\theta_{L}} u_{L}^{j}
$$

\section{Appendix C: Proposition 3’s Proof}

First consider single period bank competition, the borrower located at a distance $x$ from bank $I$ is indifferent between lending from bank $I$ and lending from bank $E$ if

$$
u_{L}^{I}-w_{I} x=u_{L}^{E}-w_{E}(1-x)
$$

so

$$
x=\frac{w_{E}+u_{L}^{I}-u_{L}^{E}}{w_{I}+w_{E}}
$$

The lower risk borrowers located in the $x$ left loan to the local bank, other borrowers will loan to the foreign banks, both banks use $u_{L}^{I}, u_{L}^{E}$ as their decision variables.

Local banks' profit is

$\Pi_{\text {new }}^{s I}=\lambda(1-v)\left[\left(1-\theta_{L}\right) X-(1+M) u_{L}^{I}-\rho^{I}\right] \frac{w_{E}+u_{L}^{I}-u_{L}^{E}}{w_{I}+w_{E}}(\mathrm{C} 3)$

Foreign banks' profit is

$\Pi_{\text {new }}^{s E}=\lambda(1-v)\left[\left(1-\theta_{L}\right) X-(1+M) u_{L}^{E}-\rho^{E}\right] \frac{w_{I}+u_{L}^{E}-u_{L}^{I}}{w_{I}+w_{E}}($

Both banks choose appropriate $u_{L}^{I}, u_{L}^{E}$ to maximize their own profit:

$$
\frac{\partial \pi_{\text {new }}^{\text {sI }}}{\partial u_{L}^{I}}=\frac{\partial \pi_{\text {new }}^{s E}}{\partial u_{L}^{E}}=0
$$

Then we get

$$
\begin{aligned}
& u_{L}^{I}=\frac{1-\theta_{L}}{1+M} X-\frac{2 \rho^{I}+\rho^{E}}{3(1+M)}-\frac{2 w_{E}+w_{I}}{3}, \\
& u_{L}^{E}=\frac{1-\theta_{L}}{1+M} X-\frac{2 \rho^{E}+\rho^{I}}{3(1+M)}-\frac{2 w_{I}+w_{E}}{3} \\
& x_{L}^{S}=\frac{w_{E}+\frac{\rho^{E}-\rho^{I}}{3(1+M)}+\frac{w_{I}-w_{E}}{3}}{w_{I}+w_{E}}
\end{aligned}
$$

Loan contract offered by the local bank is as follows 


$$
\begin{aligned}
& R_{L}^{I}=X-\frac{\theta_{H}}{\theta_{H}-\theta_{L}}\left[\frac{1-\theta_{L}}{1+M} X-\frac{2 \rho^{I}+\rho^{E}}{3(1+M)}-\frac{2 w_{E}+w_{I}}{3}\right], \\
& C_{L}^{I}=\frac{1-\theta_{H}}{\theta_{H}-\theta_{L}}\left[\frac{1-\theta_{L}}{1+M} X-\frac{2 \rho^{I}+\rho^{E}}{3(1+M)}-\frac{2 w_{E}+w_{I}}{3}\right]
\end{aligned}
$$

Loan contract offered by the foreign bank is as follows

$$
\begin{aligned}
& R_{L}^{E}=X-\frac{\theta_{H}}{\theta_{H}-\theta_{L}}\left[\frac{1-\theta_{L}}{1+M} X-\frac{2 \rho^{E}+\rho^{I}}{3(1+M)}-\frac{2 w_{I}+w_{E}}{3}\right] \\
& C_{L}^{E}=\frac{1-\theta_{H}}{\theta_{H}-\theta_{L}}\left[\frac{1-\theta_{L}}{1+M} X-\frac{2 \rho^{E}+\rho^{I}}{3(1+M)}-\frac{2 w_{I}+w_{E}}{3}\right]
\end{aligned}
$$

Both banks' profits are respectively

$$
\Pi_{\mathrm{new}}^{\text {sI }}=\frac{\lambda(1-v)}{9(1+M)\left(w_{I}+w_{E}\right)}\left[\rho^{E}-\rho^{I}+(1+M)\left(w_{I}+2 w_{E}\right)\right]^{2}
$$

Local Banks in the new customer market profits for

$$
\Pi_{\text {new }}^{m I, t}=\max \lambda\left[\pi_{\text {new }}^{m I, t}\left(u_{L}^{I, t}, x_{L}^{m, t}\right)+\delta\left(\lambda E \pi_{\text {new }}^{m I, t+1}\left(u_{L}^{I, t+1}, x_{L}^{m, t+1}\right)+E \pi_{\text {old }}^{m I, t+1}\left(u_{L}^{I, t+1}, x_{L}^{m, t}\right)\right)\right]
$$

where

$$
\begin{aligned}
\pi_{\mathrm{new}}^{m I, t}\left(u_{L}^{m I, t}, x_{L}^{m, t}\right)= & \lambda(1-v)\left[\left(1-\theta_{L}\right) X-(1+M) u_{L}^{m I, t}-\rho^{I}\right] \times\left[\frac{w_{E}}{w_{I}+w_{E}}+\frac{u_{L}^{m I, t}-u_{L}^{m E, t}+\delta E u_{L}^{m E, t+1}-\delta E u_{L}^{m I, t+1}}{(1-\delta)\left(w_{I}+w_{E}\right)}\right] \\
\pi_{\text {old }}^{m I, t+1}\left(u_{L}^{m I, t+1}, x_{L}^{m, t}\right)= & \lambda(1-v) \int_{0}^{x_{L}^{m, t}}\left[\left(1-\theta_{L}\right) X-(1+M)\left(u_{L}^{m E, t+1}+\left(w_{I}+w_{E}\right) \xi-w_{E}\right)-\rho^{I}\right] \mathrm{d} \xi \\
= & \lambda(1-v)\left\{\left[\left(1-\theta_{L}\right) X-(1+M)\left(u_{L}^{m E, t+1}-w_{E}\right)-\rho^{I}\right]\left[\frac{w_{E}}{w_{I}+w_{E}}+\frac{u_{L}^{m I, t}-u_{L}^{m E, t}+\delta E u_{L}^{m E, t+1}-\delta E u_{L}^{m I, t+1}}{(1-\delta)\left(w_{I}+w_{E}\right)}\right]\right. \\
& \left.-\frac{1}{2}(1+M)\left(w_{I}+w_{E}\right)\left[\frac{w_{E}}{w_{I}+w_{E}}+\frac{u_{L}^{m I, t}-u_{L}^{m E, t}+\delta E u_{L}^{m E, t+1}-\delta E u_{L}^{m I, t+1}}{(1-\delta)\left(w_{I}+w_{E}\right)}\right]^{2}\right\}
\end{aligned}
$$

The both banks choose appropriate $u_{L}^{m I, t}, u_{L}^{m E, t}$ to maximize their profits

$$
\frac{\partial \prod_{\text {new }}^{m I, t}}{\partial u_{L}^{m l, t}}=\frac{\partial \prod_{\text {new }}^{m E, t}}{\partial u_{L}^{m E, t}}=0
$$

When the market achieves steady state, the banks' profits and borrowers' revenue change no longer, and the loan contracts offered by each bank every period are the same. According to the Proposition 2 that the two banks' profit means that customer benefits unchanged, so the steady-state condition is:

$$
u_{L}^{m I, t}=E u_{L}^{m I, t+1}, u_{L}^{m E, t}=E u_{L}^{m E, t+1}
$$

So we can get

$$
\begin{aligned}
& u_{L}^{m I, t}=\frac{1-\theta_{L}}{1+M} X-\frac{2 \rho^{I}+(1-\delta) \rho^{E}}{(3-\delta)(1+M)}-\frac{2(1-\delta) w_{E}+\left(1-\delta^{2}\right) w_{I}}{(3-\delta)(1+\delta)} \\
& u_{L}^{m E, t}=\frac{1-\theta_{L}}{1+M} X-\frac{2 \rho^{E}+(1-\delta) \rho^{I}}{(3-\delta)(1+M)}-\frac{2(1-\delta) w_{I}+\left(1-\delta^{2}\right) w_{E}}{(3-\delta)(1+\delta)} \\
& x_{L}^{m}=\frac{1}{(3-\delta)(1+M)\left(w_{I}+w_{E}\right)}\left\{(1+\delta)\left(\rho^{E}-\rho^{I}\right)+\left[(1-\delta) w_{I}+2 w_{E}\right](1+M)\right\}
\end{aligned}
$$

The loan the contract offered by local bank is

$$
\begin{aligned}
& R_{L}^{m I, t}=X-\frac{\theta_{H}}{\theta_{H}-\theta_{L}}\left[\frac{1-\theta_{L}}{1+M} X-\frac{2 \rho^{I}+(1-\delta) \rho^{E}}{(3-\delta)(1+M)}-\frac{2(1-\delta) w_{E}+\left(1-\delta^{2}\right) w_{I}}{(3-\delta)(1+\delta)}\right], \\
& C_{L}^{m I, t}=\frac{1-\theta_{H}}{\theta_{H}-\theta_{L}}\left[\frac{1-\theta_{L}}{1+M} X-\frac{2 \rho^{I}+(1-\delta) \rho^{E}}{(3-\delta)(1+M)}-\frac{2(1-\delta) w_{E}+\left(1-\delta^{2}\right) w_{I}}{(3-\delta)(1+\delta)}\right]
\end{aligned}
$$


The loan the contract offered by foreign bank is

$$
\begin{aligned}
& R_{L}^{m E, t}=X-\frac{\theta_{H}}{\theta_{H}-\theta_{L}}\left[\frac{1-\theta_{L}}{1+M} X-\frac{2 \rho^{E}+(1-\delta) \rho^{I}}{(3-\delta)(1+M)}-\frac{2(1-\delta) w_{I}+\left(1-\delta^{2}\right) w_{E}}{(3-\delta)(1+\delta)}\right] \\
& C_{L}^{m E, t}=\frac{1-\theta_{H}}{\theta_{H}-\theta_{L}}\left[\frac{1-\theta_{L}}{1+M} X-\frac{2 \rho^{E}+(1-\delta) \rho^{I}}{(3-\delta)(1+M)}-\frac{2(1-\delta) w_{I}+\left(1-\delta^{2}\right) w_{E}}{(3-\delta)(1+\delta)}\right]
\end{aligned}
$$

Two banks' profits are as follows:

$$
\begin{aligned}
\Pi_{\mathrm{new}}^{m I} & =\frac{\left[(1-\delta)(1+\delta \lambda)+2 \delta-\frac{\delta}{2}(1+\delta)\right] \lambda(1-v)}{(3-\delta)^{2}(1+\delta)\left(w_{I}+w_{E}\right)(1+M)}\left\{(1+\delta)\left(\rho^{E}-\rho^{I}\right)+(1+M)\left[(1-\delta) w_{I}+2 w_{E}\right]\right\}^{2} \\
\Pi_{\mathrm{new}}^{m E} & =\frac{\left[(1-\delta)(1+\delta \lambda)+2 \delta-\frac{\delta}{2}(1+\delta)\right] \lambda(1-v)}{(3-\delta)^{2}(1+\delta)\left(w_{I}+w_{E}\right)(1+M)}\left\{(1+\delta)\left(\rho^{I}-\rho^{E}\right)+(1+M)\left[(1-\delta) w_{E}+2 w_{I}\right]\right\}^{2}
\end{aligned}
$$

We analyze how the cost affects the banks' profit by (D16), (D17)

$$
\operatorname{sgn}\left(\frac{\partial \Pi_{\text {new }}^{m I}}{\partial \rho^{I}}\right)=-\left\{(1+\delta)\left(\rho^{E}-\rho^{I}\right)+(1+M)\left[(1-\delta) w_{I}+2 w_{E}\right]\right\}<0
$$

We analyze how the transaction cost affects the banks' profit by (D16), (D17)

$$
\operatorname{sgn}\left(\frac{\partial \Pi_{\text {new }}^{m I}}{\partial w_{I}}\right)=-\operatorname{sgn}\left\{(1+\delta)\left(\rho^{E}-\rho^{I}\right)+(1+M)\left[2 \delta w_{E}-(1-\delta) w_{I}\right]\right\}
$$

